\title{
əEvaluating the Leeway Coefficient of Ocean Drifters Using Operational Marine Environmental Prediction Systems 0
}

\author{
Graig Sutherland, ${ }^{\mathrm{a}}$ Nancy Soontiens, ${ }^{\mathrm{b}}$ Fraser Davidson, ${ }^{\mathrm{b}}$ Gregory C. Smith, ${ }^{\mathrm{a}}$ Natacha Bernier, ${ }^{\mathrm{a}}$ \\ Hauke Blanken, ${ }^{c}$ Douglas Schillinger, ${ }^{\mathrm{d}}$ Guillaume Marcotte, ${ }^{\mathrm{e}}$ Johannes Röhrs, ${ }^{\mathrm{f}}$ \\ Knut-Frode Dagestad, ${ }^{\mathrm{g}}$ Kai H. Christensen, ${ }^{\mathrm{f}, \mathrm{h}}$ AND $\emptyset_{\text {YVIND BreiviK }}^{\mathrm{g}, \mathrm{i}}$

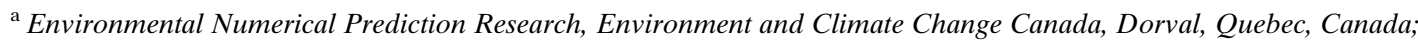 \\ ${ }^{\mathrm{b}}$ North Atlantic Fisheries Center, Fisheries and Oceans Canada, St. John's, Newfoundland and Labrador, Canada; \\ ${ }^{\mathrm{c}}$ Institute of Ocean Sciences, Fisheries and Oceans Canada, Sidney, British Columbia, Canada; ${ }^{\mathrm{d}}$ Bedford Institute

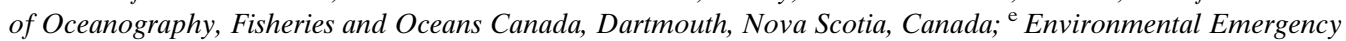 \\ Response Section, Environment and Climate Change Canada, Dorval, Quebec, Canada; ${ }^{\mathrm{f}}$ Norwegian Meteorological \\ Institute, Oslo, Norway; ${ }^{\mathrm{g}}$ Norwegian Meteorological Institute, Bergen, Norway; ${ }^{\mathrm{h}}$ Department of Geosciences, \\ University of Oslo, Oslo, Norway, ${ }^{i}$ Geophysical Institute, University of Bergen, Bergen, Norway
}

(Manuscript received 28 January 2020, in final form 28 July 2020)

\begin{abstract}
The water following characteristics of six different drifter types are investigated using two different operational marine environmental prediction systems: one produced by Environment and Climate Change Canada (ECCC) and the other produced by MET Norway (METNO). These marine prediction systems include ocean circulation models, atmospheric models, and surface wave models. Two leeway models are tested for use in drift object prediction: an implicit leeway model where the Stokes drift is implicit in the leeway coefficient, and an explicit leeway model where the Stokes drift is provided by the wave model. Both leeway coefficients are allowed to vary in direction and time in order to perfectly reproduce the observed drifter trajectory. This creates a time series of the leeway coefficients that exactly reproduce the observed drifter trajectories. Mean values for the leeway coefficients are consistent with previous studies that utilized direct observations of the leeway. For all drifters and models, the largest source of variance in the leeway coefficient occurs at the inertial frequency and the evidence suggests it is related to uncertainties in the ocean inertial currents.
\end{abstract}

KEYWORDS: Atmosphere-ocean interaction; Lagrangian circulation/transport; Trajectories; Buoy observations; Operational forecasting

\section{Introduction}

Accurate knowledge of surface currents are important for predicting the transport of buoyant material in the ocean (Christensen et al. 2018). Examples of typical material in the ocean are oil spills (Spaulding 2017), marine debris (van Sebille et al. 2015; Jansen et al. 2016), and natural occurring material related to biology such as fish eggs and larvae (Sundby 1983). In general, the modeling of material transport assumes that the only dynamic physical property of the material is its buoyancy, and the horizontal motion is that of a passive tracer. However, for objects at the surface it is common to add direct wind forcing on the object, commonly referred to as "leeway," but also the terms "windage" or "wind slip" are sometimes used (Niiler et al. 1995), in addition to the ocean currents. The windage can be derived from the ratio of air-side drag to the

¿ Denotes content that is immediately available upon publication as open access.

Supplemental information related to this paper is available at the Journals Online website: https://doi.org/10.1175/JTECH-D-200013.s1.

Corresponding author: Graig Sutherland, graigory.sutherland@ canada.ca ocean-side drag (Kirwan et al. 1975), but in practice it also compensates for effects due to finite vertical resolution in the ocean model (Isern-Fontanet et al. 2017; Tamtare et al. 2019), missing physics such as the Stokes drift (van den Bremer and Breivik 2018), or uncertainties in the operational prediction system (Dagestad and Röhrs 2019). The horizontal motion will also vary with depth due to the rapid decay of the Stokes drift with increasing depth (Breivik et al. 2014) and unresolved shear near the ocean surface (Laxague et al. 2018).

In general, the leeway is often parameterized as a linear function of the wind speed (Breivik et al. 2011). While the leeway coefficient has been shown to be equivalent to the ratio of the air-side drag to the water-side drag (Kirwan et al. 1975), it is far from trivial on how to estimate the drag ratio for an object bobbing at the ocean surface. This is especially true for more exotic objects than spherical drifters (Breivik et al. 2012). Therefore, it was suggested by Allen and Plourde (1999) and Breivik et al. (2011) that the leeway coefficient should be estimated using a direct method where detailed observations of the relative velocity between the drifter and the ocean current are compared with the wind velocity. Experiments exist for estimating the leeway coefficient using the direct method for some ocean drifters (Niiler et al. 1995; Poulain and Gerin 2019), as well as a wide range of objects encountered in search and rescue (Allen 2005; Breivik et al. 2011). However, these experiments are relatively rare, expensive and rely on the universality of the calculated leeway, i.e., a drift object 
taxonomy (Allen and Plourde 1999; Allen 2005; Breivik and Allen 2008), which is applicable to a class of drifting objects (Breivik et al. 2011). In addition, the direct method does not directly assess the ability to predict the drift trajectory using operational marine prediction systems, which will include effects due to finite resolution and parameterized physics.

So what is the best method for determining an optimal leeway coefficient to use in an operational prediction system? The leading method used to date is to calculate a skill score based on the observed and modeled trajectories using a range of values for the leeway coefficients (Toner et al. 2001; Molcard et al. 2009; Liu and Weisberg 2011; Röhrs et al. 2012; Dagestad and Röhrs 2019). However, the skill scores in these studies are all based on the separation distance, or by the time-averaged separation distance as in the score by Liu and Weisberg (2011), between the two trajectories, which implies that they are sensitive to the timing of the errors as large errors early in the trajectory will have a tendency to accumulate over time, especially in regions with appreciable horizontal shear. In addition, most of these studies restrict the leeway coefficient to a scalar (Röhrs et al. 2012; Dagestad and Röhrs 2019) and may struggle in regions with large uncertainties in oscillating currents, e.g., inertial oscillations, which can have a significant impact on drift prediction at time scales on the order of the inertial period (Christensen et al. 2018).

In this paper we take a new approach to estimating the leeway coefficient. In this approach, the leeway coefficient is allowed to vary in magnitude, direction, and time in order to reproduce an exact trajectory given a particular input of ocean, wind, and wave fields from two operational prediction systems. The model velocities are interpolated to the drifter positions in time and the leeway coefficient can be estimated directly. This has two large advantages to using forecast skill scores: 1) that all the velocity values are equally weighted in time, and 2) that the maximum of the leeway probability distribution function will provide the best estimate assuming the forcing models are unbiased. As this method allows the leeway coefficients to vary in time in order to give a perfect trajectory, it also provides statistics that can be associated with uncertainties in the prediction systems. The results are presented using six different types of drifters and two operational prediction systems for the ocean current, wind, and Stokes drift; one from Environment and Climate Change Canada (ECCC) and the other from MET Norway (METNO).

The outline is as follows. Section 2 presents the leeway models used in this study. Details about the drifters and the two operational prediction systems are found in section 3. Results are presented in section 4 followed by a discussion in section 5 and a summary of the results in section 6 .

\section{Leeway model}

The standard leeway model (Allen and Plourde 1999; Allen 2005) as implemented by Breivik and Allen (2008) and more recently by Dagestad et al. (2018) has all the effects due to finite resolution and missing physics, including the Stokes drift, implicit in the leeway coefficient and is given by the equation

$$
\mathbf{u}_{d}=\mathbf{u}_{o}+\boldsymbol{\alpha} \mathbf{U}_{10},
$$

where $\mathbf{u}_{d}$ is the drift velocity vector, $\mathbf{u}_{o}$ is the ocean velocity vector at the effective depth of the drifter, $\mathbf{U}_{10}$ is the $10 \mathrm{~m}$ wind speed vector, and $\boldsymbol{\alpha}$ is the leeway coefficient. Henceforth, (1) will be referred to as the implicit leeway model and $\boldsymbol{\alpha}$ is the implicit leeway coefficient. The coefficient $\boldsymbol{\alpha}$ is commonly a scalar, implying the drag is only in the along-wind direction, but it can also be a vector as some objects at sea have implicit leeway coefficients with both downwind and crosswind components (Allen 2005). The implicit leeway coefficient is used to parameterize a broad range of processes from a direct wind drag on the drifter (Niiler et al. 1995), to compensate for missing physics due to feedback on the forcing fields or compensate for inadequate resolution, and most prominently the Stokes drift, which is the Lagrangian drift due to the surface waves. For a fully developed sea, the Stokes drift at the surface is typically about $1.0 \%$ to $1.5 \%$ of $\mathbf{U}_{10}$ and decays rapidly with depth (Breivik et al. 2014, 2016).

As the Stokes drift is increasingly available from operational wave prediction systems, it can be included explicitly in the trajectory model. We will define an explicit leeway model, which explicitly includes the contribution from the Stokes drift, as

$$
\mathbf{u}_{d}=\mathbf{u}_{o}+\mathbf{u}_{s}+\boldsymbol{\beta} \mathbf{U}_{10}
$$

where $\mathbf{u}_{s}$ is the Stokes drift at the effective depth of the drifter and $\boldsymbol{\beta}$ is the leeway coefficient when the Stokes drift is explicitly included. We will refer to this model as the explicit leeway model. As mentioned in the previous paragraph, the Stokes drift is reasonably estimated by using a percentage of the wind velocity and is often not explicitly included in leeway modeling (Breivik et al. 2011). In general, the depth-dependent Stokes drift is not a standard output variable of ocean wave prediction systems, but can be estimated from the more common surface Stokes drift $\left(\mathbf{u}_{s 0}\right)$ and assuming the exponential decay can be estimated by a single wavenumber $\bar{k}$; i.e. (Breivik et al. 2014),

$$
\mathbf{u}_{s}=\mathbf{u}_{s 0} e^{2 \bar{k} z}
$$

where $z$ is the depth (negative from surface) and $\bar{k}$ is the vertical wavenumber, which can be estimated from the surface Stokes drift and the Stokes transport $\left(\mathbf{T}_{\mathrm{st}}\right)$

$$
\bar{k}=\frac{\left|\mathbf{u}_{s 0}\right|}{2\left|\mathbf{T}_{\mathrm{st}}\right|},
$$

where the Stokes transport is defined as the vertical integral of the Stokes drift

$$
\mathbf{T}_{s t}=\int_{-\infty}^{0} \mathbf{u}_{s} d z,
$$

and is a common output of ocean wave prediction systems.

Estimates of $\mathbf{u}_{s 0}$ and $\mathbf{u}_{s \mathrm{t}}$ can also be made from the significant wave height ( $H_{S}$ : the mean height of the highest $1 / 3$ waves) and the mean zero-upcrossing period $\left(T_{z 0}\right.$ : the mean period between successive times when the water elevation crosses from 


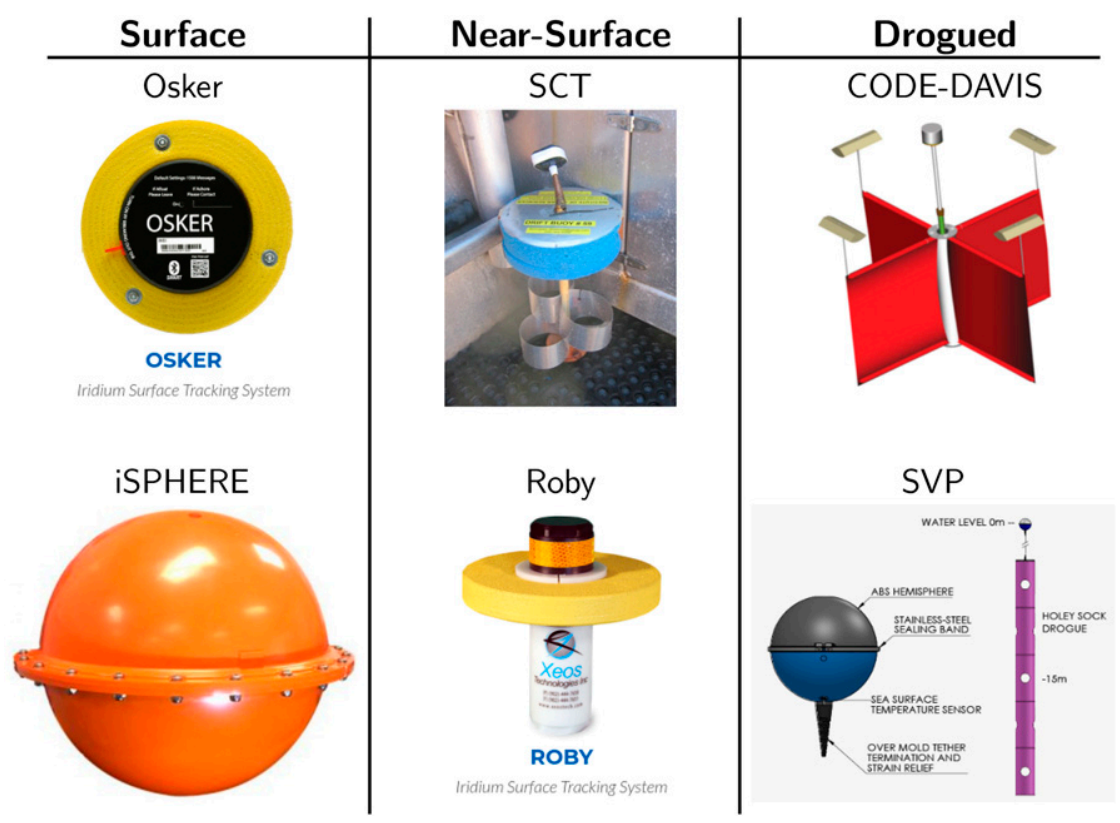

FIG. 1. Drifters used in the experiment.

below to above the mean elevation) if only these estimates of the wave field are present. The magnitude of the surface Stokes drift and the Stokes transport can be estimated to be

$$
u_{s 0}=\frac{\pi^{3} H_{S}^{2}}{g T_{z 0}^{3}}
$$

and

$$
T_{\text {st }}=\frac{2 \pi H_{S}^{2}}{16 T_{z 0}}
$$

respectively. The direction is either given by a mean wave direction given by the wave model or assumed to be in the direction of the wind. It is important to note that (6) and (7) are simplifications based on a deep-water dispersion relation of $\bar{k}=4 \pi^{2} /\left(g T_{z 0}^{2}\right)$ and assuming the waves are predominantly unidirectional. The validity of using (6) and (7) will depend on the frequency and directional distribution of the surface waves as well as the local depth and surface current, which can impact the dispersion relation for surface gravity waves (Kirby and Chen 1989).

\section{Data and methods}

\section{a. Drifters}

Six different types of drifters were deployed in this experiment, each representing a different effective depth with some having drogues to increase the ocean drag. These drifters are classified into three groups: surface, near-surface, and drogued. This classification is predominantly a function of the wind response, with surface drifters having the largest wind effect, drogued having the least, and near-surface being somewhat intermediate. Therefore, these classifications are only loosely based on their effective depth and are more strongly related to the ratio of ocean-side drag to wind-side drag. An image of each drifter is shown in Fig. 1.

We use two types of surface drifter, the disc shaped Osker drifter (Xeos Technologies Inc., Canada) and the spherical iSPHERE drifter (MetOcean, Canada). The Osker drifter is $12.7 \mathrm{~cm}$ in diameter and $5.1 \mathrm{~cm}$ height and is encased in a spherical foam ring of diameter $20.3 \mathrm{~cm}$ and height of $2 \mathrm{~cm}$. The iSPHERE drifter is a slightly flattened sphere with a horizontal diameter of $39 \mathrm{~cm}$ and a vertical diameter of $31 \mathrm{~cm}$. The iSPHERE drifters have been shown to follow the surface currents plus the surface Stokes drift (Röhrs et al. 2012) and are often used to represent the drift trajectories of oil (Beloire et al. 2011). Therefore, we will also assume that both of the surface drifters have an effective depth of $0 \mathrm{~cm}$ (Tables 1 and 2).

In addition, there are two cylindrical drifters, which we will refer to as near-surface drifters, equipped with foam rings for flotation. These are the Roby drifter (Xeos Technologies Inc.) and the Surface Circulation Tracker (SCT) (Oceanetic Measurement Ltd., Canada). The Roby drifter is $5.7 \mathrm{~cm}$ in diameter and $21 \mathrm{~cm}$ in length with a $20.3 \mathrm{~cm}$ diameter foam collar on the top for extra buoyancy. The SCT drifter is $50 \mathrm{~cm}$ in height with an expected draft of $33 \mathrm{~cm}$ and has a foam collar that is $23 \mathrm{~cm}$ in diameter and $7.5 \mathrm{~cm}$ thick. The effective depth of the Roby and SCT drifter is estimated to be 10 and $20 \mathrm{~cm}$, respectively.

The final two drifters use drogues and are the Surface Velocity Program (SVP) drifter (Niiler et al. 1995) and the Coastal Ocean Dynamics Experiment (CODE) drifter (Davis 1985). The CODE drifter has a sail drogue with four sails with each sail being $0.70 \mathrm{~m}$ tall and $0.50 \mathrm{~m}$ wide and centered at 
TABLE 1. Mean and 95\% confidence interval along with the standard deviation of $\boldsymbol{\alpha}$ for each drifter and choice of forcing. Mean and standard deviation are calculated from hourly values between 6 and 18 Jun 2018 for a total of 283 measured values.

\begin{tabular}{lclcccc}
\hline \hline Drifter & Effective depth $(\mathrm{m})$ & Forcing & Mean (real) & Mean (imaginary) & Std dev (real) & Std dev (imaginary) \\
\hline Osker & 0.0 & ECCC & $0.027 \pm 0.003$ & $-0.002 \pm 0.004$ & 0.023 & 0.026 \\
Osker & 0.0 & METNO & $0.027 \pm 0.003$ & $-0.002 \pm 0.003$ & 0.019 & 0.022 \\
iSPHERE & 0.0 & ECCC & $0.029 \pm 0.003$ & $-0.001 \pm 0.004$ & 0.025 & 0.028 \\
iSPHERE & 0.0 & METNO & $0.028 \pm 0.003$ & $-0.002 \pm 0.003$ & 0.020 & 0.023 \\
Roby & 0.1 & ECCC & $0.023 \pm 0.003$ & $-0.002 \pm 0.03$ & 0.024 & 0.019 \\
Roby & 0.1 & METNO & $0.019 \pm 0.002$ & $-0.005 \pm 0.002$ & 0.015 & 0.017 \\
SCT & 0.2 & ECCC & $0.016 \pm 0.003$ & $-0.001 \pm 0.002$ & 0.019 & 0.018 \\
SCT & 0.2 & METNO & $0.015 \pm 0.003$ & $-0.003 \pm 0.003$ & 0.022 & 0.024 \\
CODE & 0.6 & ECCC & $0.009 \pm 0.003$ & $-0.008 \pm 0.004$ & 0.025 & 0.026 \\
CODE & 0.6 & METNO & $0.009 \pm 0.003$ & $-0.008 \pm 0.003$ & 0.022 & 0.021 \\
SVP & 15 & ECCC & $0.004 \pm 0.002$ & $-0.002 \pm 0.002$ & 0.018 & 0.015 \\
SVP & 15 & METNO & $-0.001 \pm 0.002$ & $0.010 \pm 0.003$ & 0.015 & 0.019 \\
\hline
\end{tabular}

$0.6 \mathrm{~m}$ depth. The SVP drifter has a 6.1-m-long holey-sock drogue with radius of $0.6 \mathrm{~m}$ and centered at $15 \mathrm{~m}$ depth. These mean depths of the drogues are taken to be the effective drift depth. While the CODE drifter drogue is in the upper meter, which for all intents and purposes is generally assumed to be the surface, due to its design the wind slippage has been found to be about $0.1 \%$ of the wind speed (Poulain and Gerin 2019), which is the same as the measured wind slippage for the SVP drifters (Lumpkin et al. 2017). Therefore, the direct wind forcing on the CODE and SVP drifters are expected to be similar and differences will be due to vertical shear and the Stokes drift.

The six drifter types were deployed on 6 June 2018 and all were operational until 18 June 2018. After this time some of the drifters stopped sending their positions. Therefore, the analysis will focus on these 12 days when all the drifters were operational. An overview of the six drifter tracks is shown in Fig. 2. The sampling rate for the drifters varied between $5 \mathrm{~min}$ and $1 \mathrm{~h}$. The velocity is calculated via forward difference of successive locations and the velocities are interpolated to hourly output by taking hourly means.

\section{b. Marine environmental prediction systems}

The ECCC operational prediction system consists of the Regional Ice-Ocean Prediction System (RIOPS) for the ocean currents, the Canadian Arctic Prediction System (CAPS) for the atmospheric winds, and the Global Deterministic Wave Prediction System (GDWPS) for the wave model providing the Stokes drift. RIOPS is a regional model based on Nucleus for European Modelling of the Ocean (NEMO; http://www.nemo-ocean.eu) with a horizontal resolution of $1 / 12^{\circ}$ (Dupont et al. 2015). Surface currents are output every $3 \mathrm{~h}$ and the surface layer depth is $1 \mathrm{~m}$. GDWPS is a global wave model based on Wavewatch III with a $1 / 4^{\circ}$ horizontal resolution and is run twice a day (Bernier et al. 2016) $1 / 4^{\circ}$. GDWPS resolves the wave spectrum with 36 logarithmically spaced frequencies between 0.035 and $1 \mathrm{~Hz}$ and 36 directions. Atmospheric model is the CAPS which is a $3-\mathrm{km}$ resolution model that covers the entire Arctic and some northern regions such as Norway. The dynamical core of CAPS is Global Environmental Multiscale (GEM), a nonhydrostatic model that solves the fully compressible Euler equations (Côté et al. 1998a,b; Girard et al. 2014), and is run operationally at ECCC. Both GEM and GDWPS output data at hourly resolution.

The METNO operational prediction system used in this study consists of the data-assimilative ocean model NorShelf (Röhrs et al. 2018), the spectral wave model WAM4 (WAMDI Group 1988; Gusdal and Carrasco 2012) and the control run

TABLE 2. Mean and 95\% confidence intervals along with standard deviation of $\boldsymbol{\beta}$ for each drifter and choice of forcing. Mean and standard deviation are calculated from hourly values between 6 and 18 Jun 2018 for a total of 283 measured values.

\begin{tabular}{lclcccc}
\hline \hline Drifter & Effective depth $(\mathrm{m})$ & Forcing & Mean (real) & Mean (imaginary) & Std dev (real) & Std dev (imaginary) \\
\hline Osker & 0.0 & ECCC & $0.016 \pm 0.003$ & $-0.001 \pm 0.003$ & 0.023 & 0.025 \\
Osker & 0.0 & METNO & $0.014 \pm 0.003$ & $-0.002 \pm 0.003$ & 0.019 & 0.022 \\
iSPHERE & 0.0 & ECCC & $0.018 \pm 0.003$ & $-0.001 \pm 0.004$ & 0.026 & 0.028 \\
iSPHERE & 0.0 & METNO & $0.015 \pm 0.003$ & $-0.001 \pm 0.003$ & 0.020 & 0.023 \\
Roby & 0.1 & ECCC & $0.012 \pm 0.003$ & $-0.001 \pm 0.003$ & 0.025 & 0.019 \\
Roby & 0.1 & METNO & $0.007 \pm 0.002$ & $-0.005 \pm 0.002$ & 0.016 & 0.017 \\
SCT & 0.2 & ECCC & $0.006 \pm 0.003$ & $0.000 \pm 0.002$ & 0.020 & 0.018 \\
SCT & 0.2 & METNO & $0.004 \pm 0.003$ & $-0.003 \pm 0.002$ & 0.023 & 0.024 \\
CODE & 0.6 & ECCC & $0.001 \pm 0.003$ & $-0.007 \pm 0.004$ & 0.025 & 0.026 \\
CODE & 0.6 & METNO & $0.001 \pm 0.003$ & $-0.008 \pm 0.003$ & 0.023 & 0.022 \\
SVP & 15 & ECCC & $0.003 \pm 0.002$ & $-0.002 \pm 0.002$ & 0.018 & 0.015 \\
SVP & 15 & METNO & $-0.001 \pm 0.002$ & $0.010 \pm 0.003$ & 0.015 & 0.019 \\
\hline
\end{tabular}




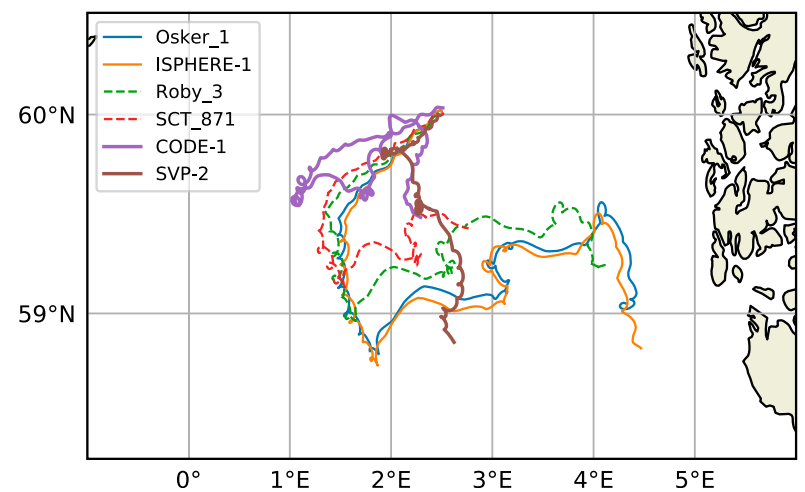

FIG. 2. Trajectories for the various drifters over the period 6-18 Jun 2018. Thin solid lines are surface drifters, dashed lines are nearsurface drifters, and thick solid lines are the drogued drifters.

from the MetCoOp Ensemble Prediction System (MEPS) (Müller et al. 2017; Bengtsson et al. 2017; Frogner et al. 2019). NorShelf is based on the Regional Ocean Modeling System (Shchepetkin and McWilliams 2005) and nested into Topaz (Xie et al. 2017), providing ocean currents with a horizontal resolution of $2.4 \mathrm{~km}$ and a vertical resolution at the surface of about $0.5-1 \mathrm{~m}$. The wave model is a version of the MyWaveWAM model set up at a $4 \mathrm{~km}$ resolution with boundary conditions in the form of two-dimensional spectra from the operational ECMWF wave forecasts. The model resolves the wave spectrum with 36 logarithmically spaced frequencies from 0.0345 to $0.9702 \mathrm{~Hz}$ and $36 \mathrm{di}$ rections. The wind forcing for both the ocean and wave models are taken from the control member of MEPS, which has a native horizontal resolution of $2.5 \mathrm{~km}$. These regional systems are forced or nested into the ECMWF global forecast system and hourly data are available from the Norwegian Meteorological Institute's thredds server (http://thredds.met.no). Wind, waves, and ocean surface values are available at hourly resolution.

The velocities produced by each the two prediction systems are linearly interpolated in space and time to each drifter track. An example for the Osker drifter track can be found in Fig. 3. There is little difference between the ECCC winds and METNO winds with both showing a peak wind speed of $18 \mathrm{~m} \mathrm{~s}^{-1}$ on 14 June 2018. The largest discrepancies between the ECCC and METNO prediction systems occurs between the ocean velocities. Figure 4 shows snapshots of the surface currents and $10 \mathrm{~m}$ winds on 13 June 2018 showing the higher variability in the higher resolution METNO ocean velocities (Fig. 4c) compared to the ECCC ocean velocities (Fig. 4a). However, there do exist similarities in large-scale features between the two ocean velocities as well as similarities in the $10 \mathrm{~m}$ wind field (Figs. $4 \mathrm{~b}$ and $4 \mathrm{~d}$ for ECCC and METNO winds, respectively). The surface Stokes drift (Fig. 3a) is also very similar between the ECCC and METNO models with the direction predominantly following the wind. Mean values for $u_{s 0} / U_{10}$ for the ECCC and METNO prediction systems are $1.2 \%$ and $1.4 \%$, respectively.

\section{c. Calculating $\boldsymbol{\alpha}$ and $\boldsymbol{\beta}$}

The implicit leeway coefficient $\boldsymbol{\alpha}$ can be calculated directly from Eq. (1) using the time series for each drifter of the modeled wind and ocean currents; i.e.,

$$
\boldsymbol{\alpha}=\frac{\mathbf{u}_{d}-\mathbf{u}_{o}}{\mathbf{U}_{10}} .
$$

The ocean velocity $\mathbf{u}_{o}$ and $10 \mathrm{~m}$ wind velocity $\mathbf{U}_{10}$ are interpolated in space and time to the location of the drifter. The interpolation is bilinear in space from the four adjacent grid points and linearly in time. The vector $\boldsymbol{\alpha}$ is the leeway coefficient, which

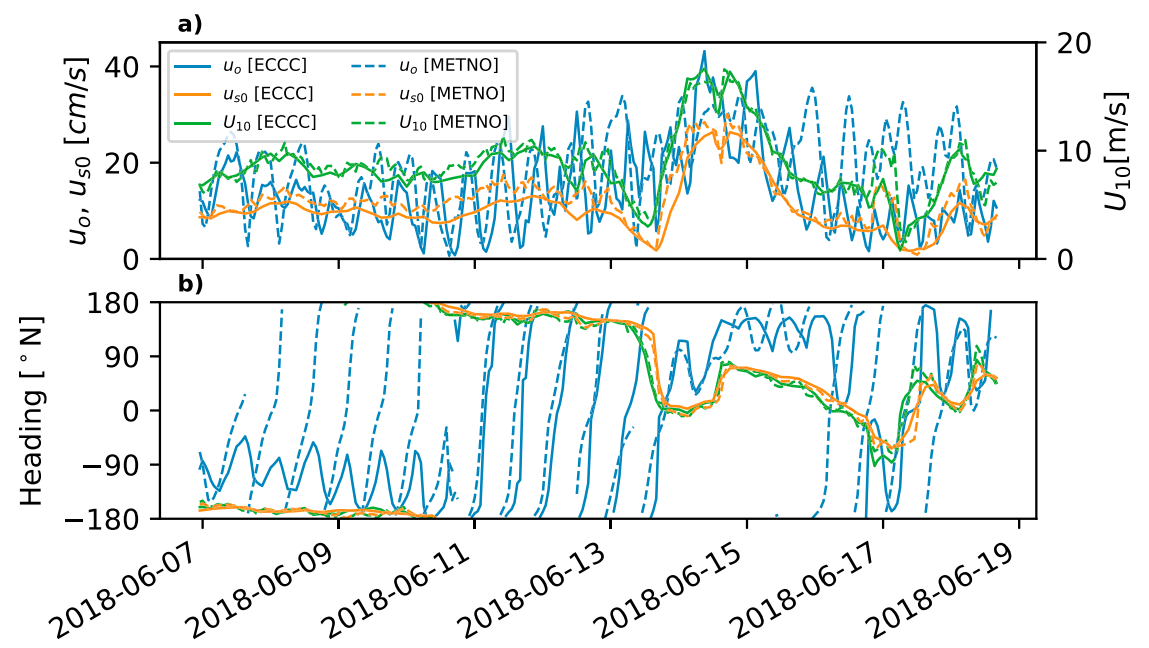

FIG. 3. Forcing time series interpolated to the Osker drift track. (a) The magnitude of the ocean current $\left(u_{\mathrm{o}}\right)$, surface Stokes drift $\left(u_{s 0}\right)$, and wind speed at $10 \mathrm{~m}\left(U_{10}\right)$ for the ECCC prediction system (solid lines) and the METNO prediction system (dashed lines). (b) The heading for the velocities in (a) in degrees clockwise from north. 


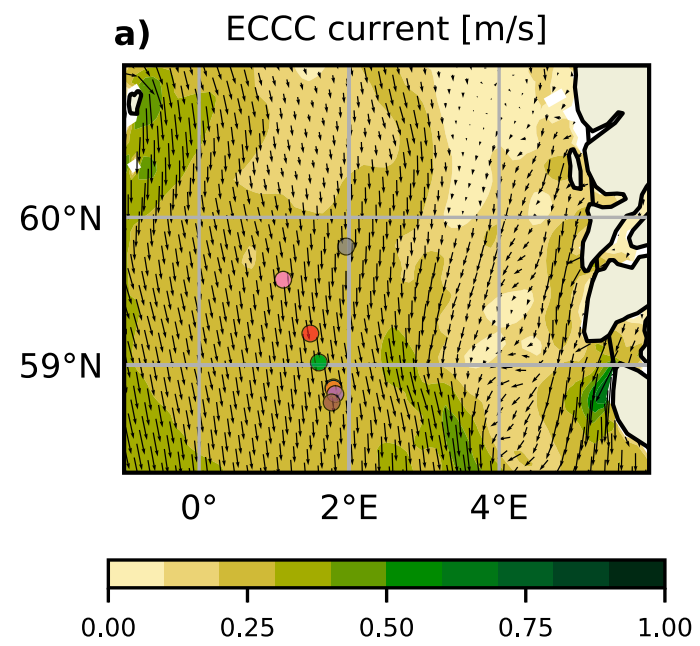

b) ECCC wind speed [knots]

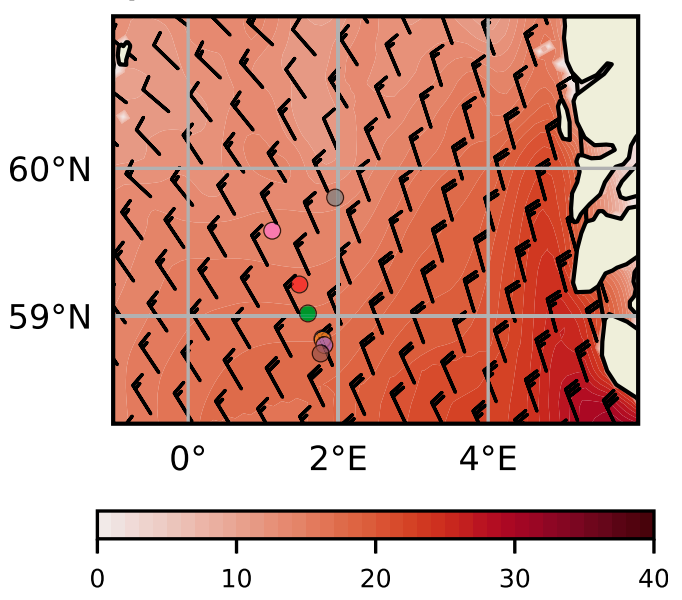

d) METNO wind speed [knots]

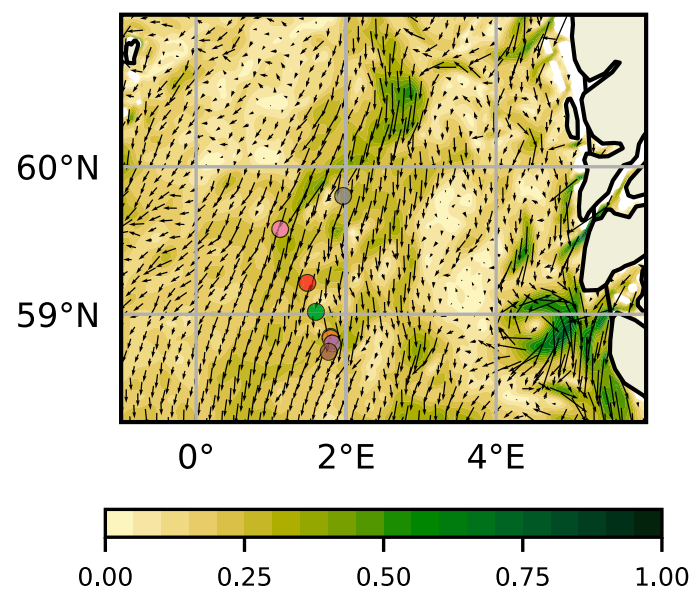

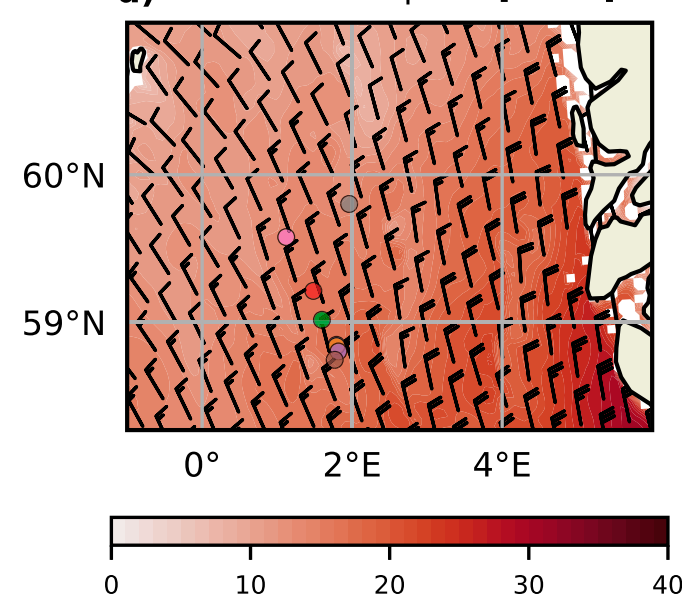

FIG. 4. Snapshots of forcing fields at 0000 UTC 13 Jun 2018. (left) Surface velocities and (right) $10 \mathrm{~m}$ wind speeds are shown for (a),(b) the ECCC prediction system and (c),(d) the METNO prediction system. Drifter locations at 0000 UTC 13 Jun 2018 are denoted by colored dots and the drifter color is shown in Fig. 2.

produces an exact prediction at each time step. Therefore, the distribution of $\boldsymbol{\alpha}$ will encompass all of the uncertainties in the model ocean and wind velocities as well as any uncertainties in the observed drift velocity. The velocity vectors are written in complex form so the real part is positive in the eastward direction and the imaginary part is positive in the northward direction. Therefore, the real part of $\boldsymbol{\alpha}$ will be in the along-wind direction and the imaginary part in the crosswind direction (negative to the right of the wind direction).

The same analysis can be applied to the explicit leeway model (2) to calculate $\boldsymbol{\beta}$ where now the Stokes drift $\mathbf{u}_{s}$ is explicitly included; i.e.,

$$
\boldsymbol{\beta}=\frac{\mathbf{u}_{d}-\mathbf{u}_{s}-\mathbf{u}_{o}}{\mathbf{U}_{10}} .
$$

Both Eqs. (8) and (9) are calculated for each recorded drifter position. This provides a time series of the complex value for $\boldsymbol{\alpha}$ (or $\boldsymbol{\beta}$ ), which can be used to estimate the mean and variance of the along-wind and crosswind components.

\section{Results}

The 2D histogram of $\boldsymbol{\alpha}$ for the surface drifters (Osker and iSPHERE) shows the mean and variance over the experiment period for both choices of environmental forcing (Fig. 5). Results for $\boldsymbol{\alpha}$ are presented in Table 1. Both the ECCC and METNO forcing yield a peak in the PDF at $\boldsymbol{\alpha}$ of about 0.03 in the along-wind direction and negligible in the crosswind direction. The standard deviation of the along-wind and crosswind components are between 0.02 and 0.03 . For each $2 \mathrm{D}$ histogram there is also the associated 1D histogram of the along-wind component (above each 2D histogram) and of the crosswind component (to the right of each 2D histogram). The mean value is shown in red, and the standard deviation of each component is shown in orange. The orange box encloses 


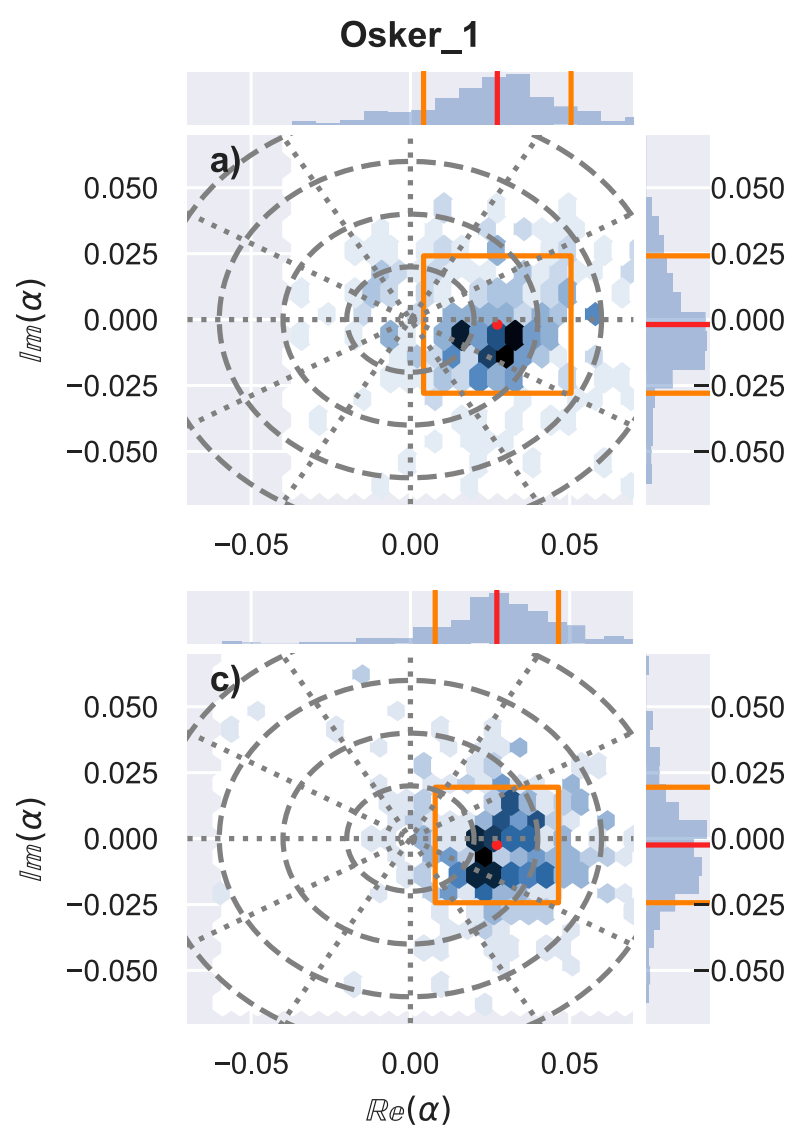

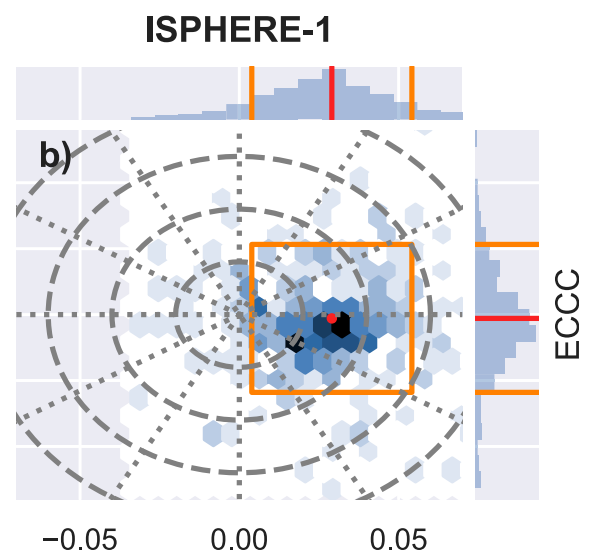

ISPHERE-1

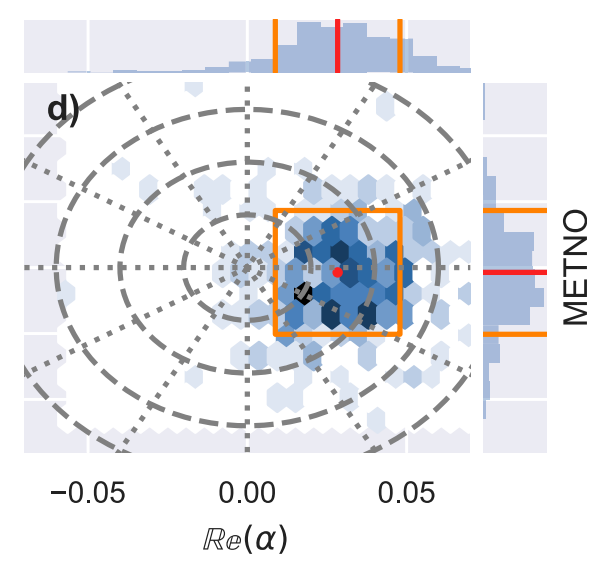

FIG. 5. Two-dimensional histograms of $\boldsymbol{\alpha}$ (implicit Stokes drift) for two of the surface drifters and two different model forcing: (a),(b) ECCC forcing and (c),(d) METNO forcing.

values that are within one standard deviation of the mean. The standard deviation is slightly higher using the ECCC forcing compared to the METNO forcing and both forcings give a standard deviation slightly greater in the crosswind compared to the along-wind direction.

The 2D histogram for when the Stokes drift is explicitly included, as in (9), is shown in Fig. 6 and the results are shown in Table 2. The along-wind component for $\boldsymbol{\beta}$ is less when the Stokes drift is included, with a reduction of 0.011 and 0.013 compared to $\boldsymbol{\alpha}$ for the ECCC and METNO forcing, respectively. In addition, the standard deviation for $\boldsymbol{\beta}$ is identical to that of $\boldsymbol{\alpha}$ suggesting that including the Stokes drift has no appreciable effect on the accuracy of the prediction over the duration of the observations.

The same analysis is performed for the near-surface drifters (Roby and SCT) and the drogued drifters (CODE and SVP). The mean, along with $95 \%$ confidence intervals, and standard deviation for the implicit and explicit Stokes drift are shown in Tables 1 and 2, respectively. The 2D histograms are not included here, but are available in the online supplementary material.

For the near-surface drifters the along-wind component of $\boldsymbol{\alpha}$ and $\boldsymbol{\beta}$ are both slightly less than for the surface drifters, especially for the SCT drifters. This is to be expected as the SCT drifters have a greater mean depth than the Roby drifters so the Stokes drift and the direct wind forcing on the drifter should be less than the surface drifters. In addition, the SCT drifters have three cylindrical rings attached to the base (Fig. 1), which will act to increase the water-side drag.

The drogued drifters have even smaller mean leeway coefficients than the other two types of drifters, with less variation between the implicit and explicit Stokes drift variation of leeway coefficient. However, explicitly including the Stokes drift for the shallower CODE drifter does reduce the required windage to a negligible value.

The error in the mean and standard deviation, as can be seen from Tables 1 and 2, does not vary greatly with drifter, choice of forcing or whether the Stokes drift is explicitly included or is implicit in the leeway coefficient. These facts suggest that the variability is most likely due to the ocean currents that are relatively uniform in the upper $15 \mathrm{~m}$ such as the barotropic tide and/or inertial currents.

Another way to look at this ideal leeway coefficient is to investigate the time series to see if there is any observed periodicity. The time series for $\boldsymbol{\alpha}$ of the Osker drifter calculated from (8) where the real and imaginary part of $\boldsymbol{\alpha}$ are shown in Figs. 7a and 7b, respectively. Variability in both the real and imaginary part are consistent with inertial oscillations, which suggests that the leeway coefficient is compensating for errors in the amplitude and/or phase of the modeled inertial currents 

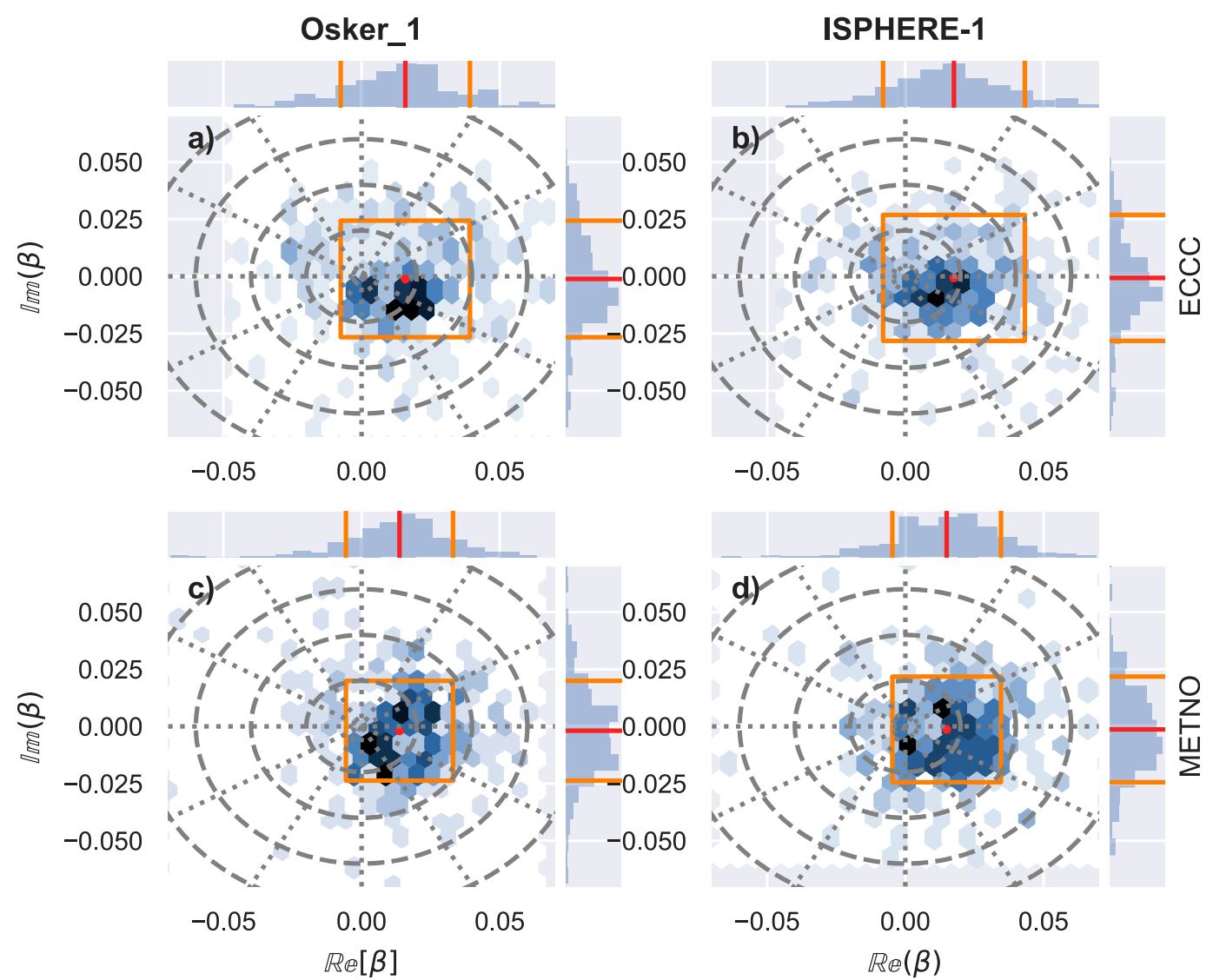

FIG. 6. Two-dimensional histograms of $\boldsymbol{\beta}$ (explicit Stokes drift) for two of the surface drifters and two different model forcing: (a),(b) ECCC forcing and (c),(d) METNO forcing.

in order to reproduce the observed trajectory. The rotary FFT, which is the FFT of the complex-valued $\boldsymbol{\alpha}$, is shown in Fig. 7c. The hourly sampling frequency over 12 days provides 283 samples providing a frequency resolution of $0.085 \mathrm{cpd}$. This is about 2.3 to 2.5 times the frequency difference between the M2 tide and the inertial frequency over the observed latitudes.

The spectrum in Fig. 7c is dominated by the large mean response, which is similar in magnitude to the mean from the time series in Fig. 5, and by peaks at the inertial frequency for both choices of forcing. This inertial peak in $\boldsymbol{\alpha}$ is nearly identical for all six drifters and both operational models (see supplementary material). For example, Fig. 8 shows the time series and FFT for the SVP drifter and the inertial peak is similar while the values at subinertial frequencies are generally less. This peak at the inertial frequency implies that the leading source of error for predictions are inertial currents. In both Figs. 7 and 8 there is a second peak near the M2 tidal frequency for the ECCC forcing, suggesting inaccuracies in the tidal component are also contributing to the velocity mismatch.

\section{Discussion}

It is inherently difficult to disentangle uncertainties associated with the marine environmental prediction systems and those associated with the leeway model in (1) and/or (2). Using two operational prediction systems allows for the partial assessment of the forcing fields, especially when the two operational systems differ. However, the errors represent the sum of all the velocity errors, normalized by the wind speed, making determination of the largest source of error difficult. For the operational systems used in this study, ECCC and METNO, the statistics of the leeway coefficient, whether it be $\boldsymbol{\alpha}$ or $\boldsymbol{\beta}$, were very similar for the two models with differences being the least for the surface drifters and greatest for the drogued drifters. This result is consistent with Dagestad and Röhrs (2019), who found that the surface drifter, specifically the iSPHERE, trajectories were strongly correlated with wind forcing and not strongly correlated with oceanic variability. As our two predictive systems provide similar wind forcing it appears that differences between the two systems are predominantly due to the oceanic component.

While our results are similar to those of Dagestad and Röhrs (2019) in that the surface drifters are much more sensitive to wind forcing than oceanic variability, the magnitude of the leeway coefficient are found to be smaller. The leeway coefficient is found to be about $3 \%$ when the Stokes drift is not included, and about $1.5 \%$ when the Stokes drift is included, while Dagestad and Röhrs (2019) found a value closer to 4\% when the Stokes drift was not included and $3 \%$ when the Stokes drift 
Osker_1

a)

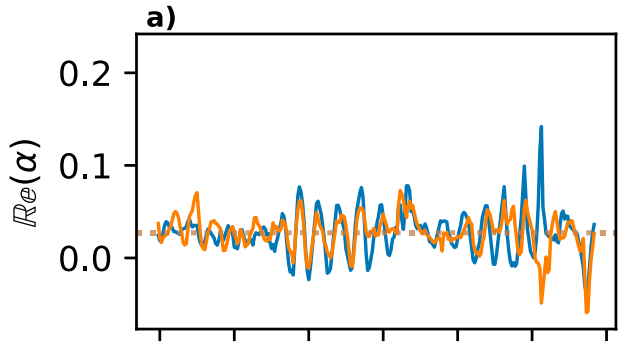

b)
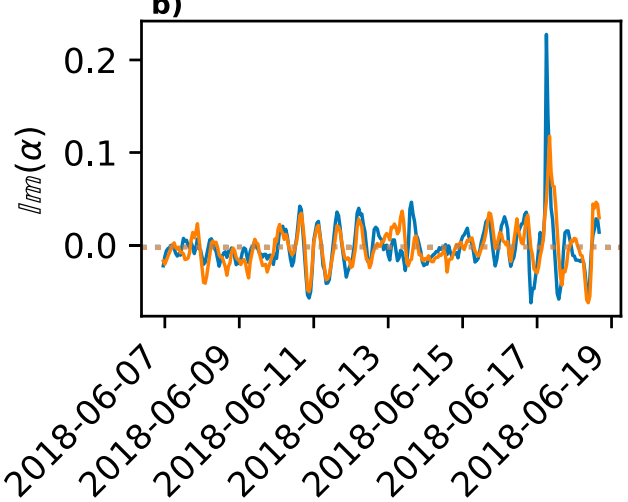

c)

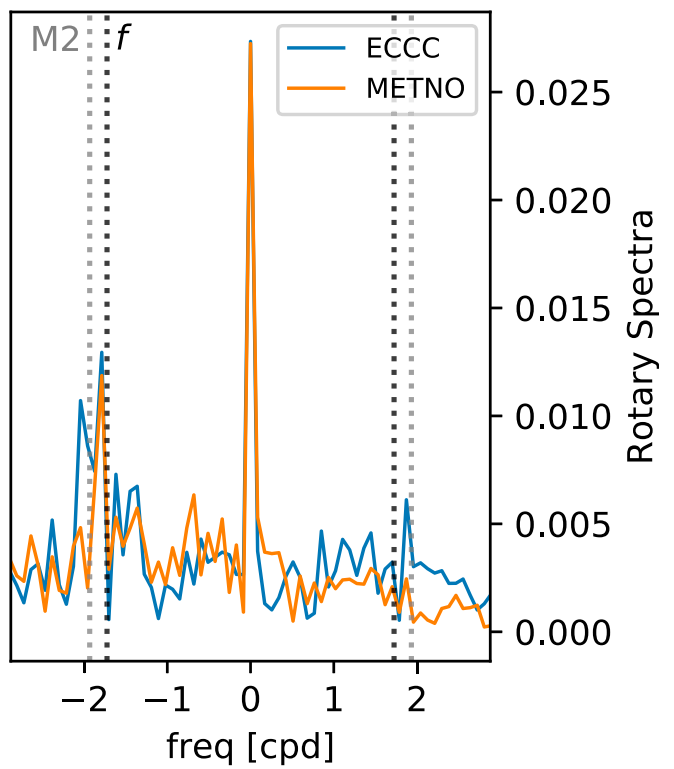

FIG. 7. Time series of (a) real part of $\boldsymbol{\alpha},(\mathrm{b})$ imaginary part of $\boldsymbol{\alpha}$, and (c) the magnitude of the rotary FFT of $\boldsymbol{\alpha}$ for the Osker drifter. Horizontal dashed lines in (a) and (b) show the temporal mean values. The vertical dashed lines in (c) shows the inertial frequency (dark) and the M2 tidal frequency (light).

is included. While it is not immediately obvious for the discrepancy, some of the reason may lie in the methodology, as we determine $\boldsymbol{\alpha}($ or $\boldsymbol{\beta})$ from the entire trajectory while Dagestad and Röhrs (2019) calculate $\boldsymbol{\alpha}$ (or $\boldsymbol{\beta}$ ) from several short forecasts of $48 \mathrm{~h}$ duration. One hypothesis is that the use of shorter forecast lead times could limit the total accumulated uncertainty in the trajectory model. Also, allowing for the leeway coefficients $\boldsymbol{\alpha}$ (or $\boldsymbol{\beta}$ ) to be vectors provides a means (at least a posteriori) to correct for uncertainties in the ocean prediction system, such as errors due to the tides and inertial oscillations.

While the method has been presented here for drifting buoys, it could easily be used for any drifting object in the ocean. For example, the leeway coefficient for a ship adrift could be estimated with available data from the operational prediction system in order to improve future predictions. Such a method could also be dynamic as the leeway coefficient could be updated as more data become available. Uncertainty in high-frequency motions in the ocean model, most notably from inertial currents, will undoubtedly influence estimates of the leeway coefficient over a short duration, but as long as data from a minimum of one inertial period are used to estimate the leeway coefficient then this uncertainty should have a minimal effect on the mean leeway coefficient.

The explicit inclusion of the Stokes drift, as calculated by a wave model, does not change the variability of the leeway coefficient and the magnitude of the Stokes drift, at least for surface objects, and can be approximated by a fraction of the wind speed. While it appears that a typical value of $1.3 \%$ (Rascle et al. 2008) is appropriate for this case, there still exists variability in the literature on the range of $0.5 \%-3 \%$ depending on the sea state (Rascle and Ardhuin 2013). Therefore, it is preferable to calculate the Stokes drift using available wave spectra, either from a numerical model or from observations, rather than a direct wind-based parameterization. Furthermore, for drifters in the upper meter but not right at the surface, it is important to calculate the $e$ folding depth and this is simplified by the use of an operational wave model.

\section{Conclusions}

Presented is an analysis of the leeway coefficient calculated for several drifter types using two different operational prediction systems. The leeway coefficient is calculated at each location for each drifter such that the prediction system exactly reproduces the observed trajectory. This method provides a time series of the leeway coefficient from which appropriate statistics can be calculated. In addition, calculating the leeway coefficient using this method provides the linear best estimate provided the forcing (currents, waves, and winds) are unbiased.

For the surface drifters, iSPHERE and the Osker, a mean wind induced drag of about $2.8 \% \pm 0.1 \%$ and $1.6 \% \pm 0.2 \%$ of the wind speed was found to reproduce the observed trajectories for the implicit and explicit leeway models, 
SVP-2

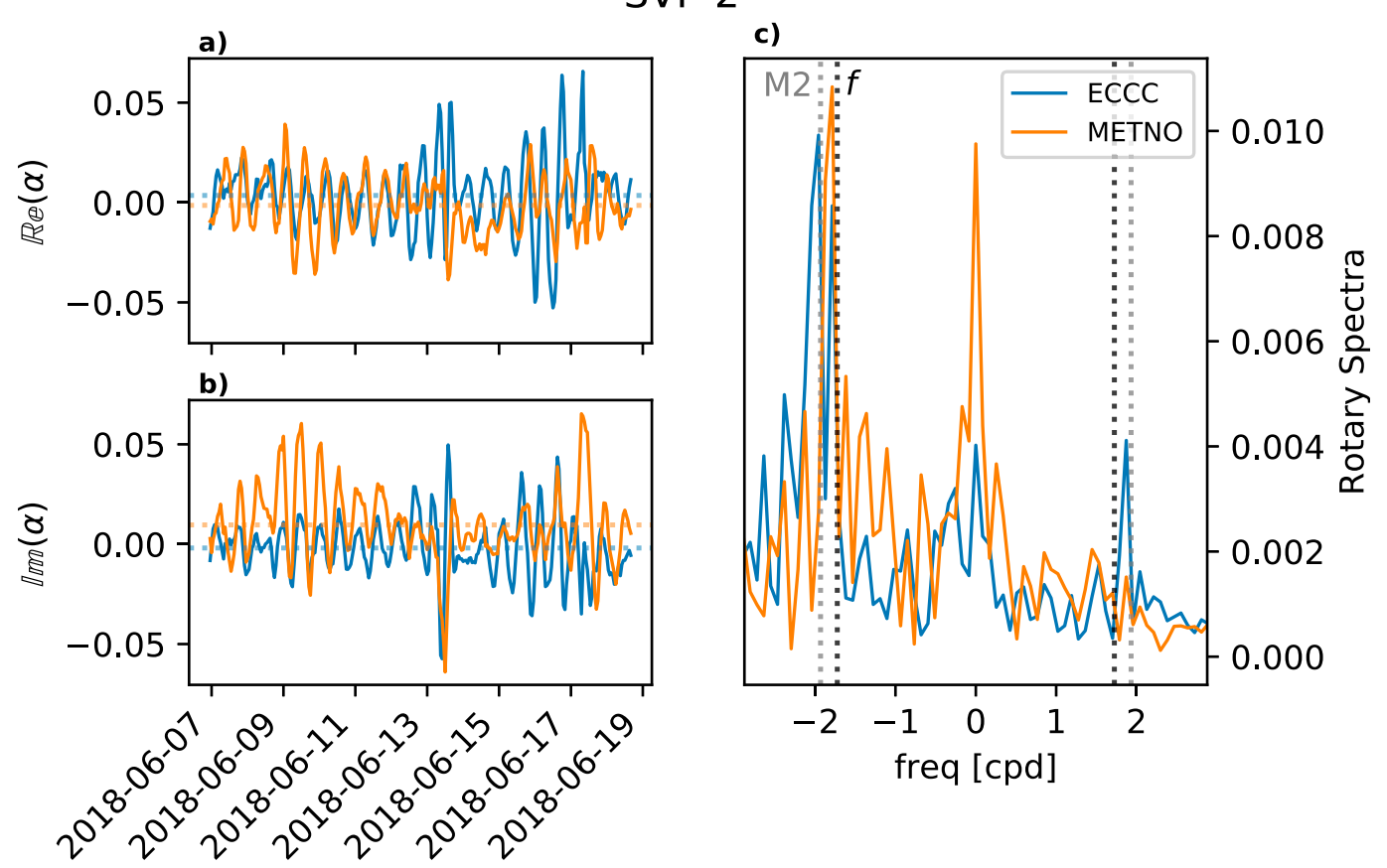

FIG. 8. Time series of (a) real part of $\boldsymbol{\alpha}$, (b) imaginary part of $\boldsymbol{\alpha}$, and (c) the magnitude of the rotary FFT of $\boldsymbol{\alpha}$ for the SVP drifter. Horizontal dashed lines in (a) and (b) show the temporal mean values and the vertical dashed lines in (c) shows the inertial frequency.

respectively, and did not depend on the choice of operational model. The standard deviation did not vary with the choice of leeway model and ranged between $2 \%$ and $3 \%$ for each of the along-wind and crosswind components, with the crosswind standard deviation being consistently larger than the along-wind standard deviation. This 3\% value for the wind drag is similar to previous reported values for the iSPHERE (Röhrs and Christensen 2015) and is the first study to look at the water following attributes for the Osker drifter. As the iSPHERE drifters are commonly used to track oil spills (Beloire et al. 2011), our study suggests that Osker drifters should be equally well suited for this purpose.

The two near-surface drifters, the Roby and SCT drifters, which are both undrogued but with slightly deeper profiles in the water, had slightly reduced values for the leeway coefficient relative to the surface drifters. The Roby drifter had a similar value for $\boldsymbol{\alpha}(\boldsymbol{\beta})$ of $2.3 \%$ (1.2\%) for the ECCC forcing and $1.9 \%$ $(0.7 \%)$ for the METNO forcing. The standard deviation between the two operational models is also slightly different with the ECCC values being $2.4 \%$ to $2.5 \%$ in the along-wind and $1.9 \%$ in the crosswind directions and the METNO values being $1.6 \%$ in the along-wind and $1.7 \%$ in the crosswind directions.

For the two drogued drifters, CODE and SVP, the leeway coefficient was found to be less than $1 \%$, which is consistent with results from previous studies (Niiler et al. 1995; Poulain and Gerin 2019). The windage on the SVP should be negligible (Niiler et al. 1995) so these results most likely represent mean biases in the ocean model over these drifter tracks. By explicitly including the Stokes drift, the CODE drifters, with a mean depth of $0.6 \mathrm{~m}$, have their along-wind leeway coefficient reduced from $0.9 \%$ to $0.1 \%$.

Analysis of the time-dependent leeway coefficient clearly shows a peak at the inertial frequency and that this peak is consistent between the choice of forcing (i.e., for both ECCC and METNO) and drifter (i.e., surface and drogued drifters). In addition, the ECCC forcing shows a second peak at the M2 tidal frequency. These peaks do not appear to be physical, but rather compensating for errors in the ocean model at these frequencies. This suggests that ocean models can be used to accurately estimate the mean leeway coefficient for drifting objects provided the time series is long enough to minimize these high-frequency uncertainties. However, for shorter time periods (hours to a couple days) it is imperative that these high-frequency motions, especially the transient response to the wind, are accurately reproduced by ocean models in order to accurately reproduce the drift (Christensen et al. 2018).

Acknowledgments. Financial support for the drifter deployments was provided through the Government of Canada's Oceans Protection Plan. The field work was carried out during the 2018 Oil on water campaign with generous assistance from NOFO, the Norwegian Clean Seas Association for Operating Companies. KHC, KFD, JR and $\varnothing \mathrm{B}$ gratefully acknowledge the financial support of the Research Council of Norway through the CIRFA project, Grant 237906.

Data availability statement. Data are freely available from the corresponding author by request. 


\section{REFERENCES}

Allen, A. A., 2005: Leeway divergence. U.S. Coast Guard Research and Development Center Tech. Rep. CG-D-05-05, 128 pp., https://apps.dtic.mil/dtic/tr/fulltext/u2/a435435.pdf.

—_, and J. V. Plourde, 1999: Review of leeway: Field experiments and implementation. U.S. Coast Guard Research and Development Center Tech. Rep. CG-D-08-99, 351 pp., https://apps.dtic.mil/dtic/tr/fulltext/u2/a366414.pdf.

Beloire, R., K. Trudel, and J. Morrison, 2011: Weathering, emulsification, and chemical dispersibility of Mississippi Canyon 252 crude oil: Field and laboratory studies. Proc. International Oil Spill Conf., Portland, OR, IPIECA, abs247, https://doi.org/ 10.7901/2169-3358-2011-1-247.

Bengtsson, L., and Coauthors, 2017: The HARMONIE-AROME model configuration in the ALADIN-HIRLAM NWP system. Mon. Wea. Rev., 145, 1919-1935, https://doi.org/10.1175/ MWR-D-16-0417.1.

Bernier, N. B., and Coauthors, 2016: Operational wave prediction system at Environment Canada: Going global to improve regional forecast skill. Wea. Forecasting, 31, 353-370, https:// doi.org/10.1175/WAF-D-15-0087.1.

Breivik, Ø., and A. A. Allen, 2008: An operational search and rescue model for the Norwegian Sea and the North Sea. J. Mar. Syst., 69, 99-113, https://doi.org/10.1016/j.jmarsys.2007.02.010.

,-- C C. Maisondieu, and J. C. Roth, 2011: Wind-induced drift of objects at sea: The leeway field method. Appl. Ocean Res., 33, 100-109, https://doi.org/10.1016/j.apor.2011.01.005.

,,,$----\frac{}{-}$, and B. Forest, 2012: The leeway of shipping containers at different immersion levels. Ocean Dyn., 62, 741752, https://doi.org/10.1007/s10236-012-0522-z.

_ _ P. A. Janssen, and J.-R. Bidlot, 2014: Approximate Stokes drift profiles in deep water. J. Phys. Oceanogr., 44, 2433-2445, https://doi.org/10.1175/JPO-D-14-0020.1.

— proximation based on the Phillips spectrum. Ocean Modell., 100, 49-56, https://doi.org/10.1016/j.ocemod.2016.01.005.

Christensen, K. H., Ø. Breivik, K.-F. Dagestad, J. Röhrs, and B. Ward, 2018: Short-term predictions of oceanic drift. Oceanography, 31 (3), 59-67, https://doi.org/10.5670/oceanog.2018.310.

Côté, J., S. Gravel, A. Méthot, A. Patoine, M. Roch, and A. Staniforth, 1998a: The operational CMC-MRB Global Environmental Multiscale (GEM) model. Part I: Design considerations and formulation. Mon. Wea. Rev., 126, 1373-1395, https://doi.org/ 10.1175/1520-0493(1998)126<1373:TOCMGE > 2.0.CO;2.

_ J.-G. Desmarais, S. Gravel, A. Méthot, A. Patoine, M. Roch, and A. Staniforth, 1998b: The operational CMC-MRB Global Environmental Multiscale (GEM) model. Part II: Results. Mon. Wea. Rev., 126, 1397-1418, https://doi.org/10.1175/15200493(1998)126<1397:TOCMGE > 2.0.CO;2.

Dagestad, K.-F., and J. Röhrs, 2019: Prediction of ocean surface trajectories using satellite derived vs. modeled ocean currents. Remote Sens. Environ., 223, 130-142, https://doi.org/10.1016/ j.rse.2019.01.001.

,$--\varnothing$. Breivik, and B. Ådlandsvik, 2018: OpenDrift v1.0: A generic framework for trajectory modeling. Geosci. Model Dev., 11, 1405-1420, https://doi.org/10.5194/gmd-11-1405-2018.

Davis, R. E., 1985: Drifter observations of coastal surface currents during CODE: The method and descriptive view. J. Geophys. Res., 90, 4741-4755, https://doi.org/10.1029/JC090iC03p04741.

Dupont, F., and Coauthors, 2015: A high-resolution ocean and seaice modelling system for the Arctic and North Atlantic Oceans. Geosci. Model Dev., 8, 1577-1594, https://doi.org/ 10.5194/gmd-8-1577-2015.
Frogner, I.-L., A. T. Singleton, M. Ø. Køltzow, and U. Andrae, 2019: Convection-permitting ensembles: Challenges related to their design and use. Quart. J. Roy. Meteor. Soc., 145, 90-106, https://doi.org/10.1002/qj.3525.

Girard, C., and Coauthors, 2014: Staggered vertical discretization of the Canadian Environmental Multiscale (GEM) model using a coordinate of the log-hydrostatic-pressure type. Mon. Wea. Rev., 142, 1183-1196, https://doi.org/10.1175/MWR-D13-00255.1.

Gusdal, Y., and A. Carrasco, 2012: Validation of the operational wave model. Norwegian Meteorological Institute Tech. Rep. 23/2012, 30 pp.

Isern-Fontanet, J., J. Ballabrera-Poy, A. Turiel, and E. GarcíaLadona, 2017: Remote sensing of ocean surface currents: A review of what is being observed and what is being assimilated. Nonlinear Processes Geophys., 24, 613-643, https://doi.org/ 10.5194/npg-24-613-2017.

Jansen, E., G. Coppini, and N. Pinardi, 2016: Drift simulation of MH370 debris using superensemble techniques. Nat. Hazards Earth Syst. Sci., 16, 1623-1628, https://doi.org/10.5194/nhess16-1623-2016.

Kirby, J. T., and T.-M. Chen, 1989: Surface waves on vertically sheared flows: Approximate dispersion relations. J. Geophys. Res., 94, 1013-1027, https://doi.org/10.1029/JC094iC01p01013.

Kirwan, A., Jr., G. McNally, M. Chang, and R. Molinari, 1975: The effect of wind and surface currents on drifters. J. Phys. Oceanogr., 5, 361-368, https://doi.org/10.1175/ 1520-0485(1975)005<0361:TEOWAS >2.0.CO;2.

Laxague, N. J., and Coauthors, 2018: Observations of nearsurface current shear help describe oceanic oil and plastic transport. Geophys. Res. Lett., 45, 245-249, https://doi.org/ 10.1002/2017GL075891.

Liu, Y., and R. H. Weisberg, 2011: Evaluation of trajectory modeling in different dynamic regions using normalized cumulative Lagrangian separation. J. Geophys. Res., 116, C09013, https://doi.org/10.1029/2010JC006837.

Lumpkin, R., T. Özgökmen, and L. Centurioni, 2017: Advances in the application of surface drifters. Annu. Rev. Mar. Sci., 9, 5981, https://doi.org/10.1146/annurev-marine-010816-060641.

Molcard, A., P. Poulain, P. Forget, A. Griffa, Y. Barbin, J. Gaggelli, J. De Maistre, and M. Rixen, 2009: Comparison between VHF radar observations and data from drifter clusters in the Gulf of La Spezia (Mediterranean Sea). J. Mar. Syst., 78, S79-S89, https://doi.org/10.1016/j.jmarsys.2009.01.012.

Müller, M., and Coauthors, 2017: AROME-MetCoOp: A Nordic convective-scale operational weather prediction model. Wea. Forecasting, 32, 609-627, https://doi.org/10.1175/WAF-D-160099.1.

Niiler, P. P., A. S. Sybrandy, K. Bi, P. M. Poulain, and D. Bitterman, 1995: Measurements of the water-following capability of holey-sock and TRISTAR drifters. Deep-Sea Res. I, 42, 1951-1964, https://doi.org/10.1016/0967-0637(95) 00076-3.

Poulain, P.-M., and R. Gerin, 2019: Assessment of the waterfollowing capabilities of CODE drifters based on direct relative flow measurements. J. Atmos. Oceanic Technol., 36, 621-633, https://doi.org/10.1175/JTECH-D-18-0097.1.

Rascle, N., and F. Ardhuin, 2013: A global wave parameter database for geophysical applications. Part II: Model validation with improved source term parameterizations. Ocean Modell., 70, 174-188, https://doi.org/10.1016/j.ocemod.2012.12.001.

__, _—, P. Queffeulou, and D. Croizé-Fillon, 2008: A global wave parameter database for geophysical applications. 
Part I: Wave-current-turbulence interaction parameters for the open ocean based on traditional parameterizations. Ocean Modell., 25, 154-171, https://doi.org/10.1016/ j.ocemod.2008.07.006.

Röhrs, J., and K. H. Christensen, 2015: Drift in the uppermost part of the ocean. Geophys. Res. Lett., 42, 10349-10356, https:// doi.org/10.1002/2015GL066733.

— — _ L. R. Hole, G. Broström, M. Drivdal, and S. Sundby, 2012: Observation-based evaluation of surface wave effects on currents and trajectory forecasts. Ocean Dyn., 62, 1519-1533, https://doi.org/10.1007/s10236-012-0576-y.

__ A. K. Sperrevik, and K. H. Christensen, 2018: NorShelf: An ocean reanalysis and data-assimilative forecast model for the Norwegian Shelf Sea. Norwegian Meteorological Institute Tech. Rep. 04/2018, 42 pp., https://doi.org/10.5281/ zenodo.2384124.

Shchepetkin, A. F., and J. C. McWilliams, 2005: The Regional Oceanic Modeling System (ROMS): A split-explicit, freesurface, topography-following-coordinate oceanic model. Ocean Modell., 9, 347-404, https://doi.org/10.1016/ j.ocemod.2004.08.002.

Spaulding, M. L., 2017: State of the art review and future directions in oil spill modeling. Mar. Pollut. Bull., 115, 7-19, https:// doi.org/10.1016/j.marpolbul.2017.01.001.
Sundby, S., 1983: A one-dimensional model for the vertical distribution of pelagic fish eggs in the mixed layer. Deep-Sea Res., 30A, 645-661, https://doi.org/10.1016/0198-0149(83)90042-0.

Tamtare, T., D. Dumont, and C. Chavanne, 2019: Extrapolating Eulerian ocean currents for improving surface drift forecasts. J. Oper. Oceanogr., https://doi.org/10.1080/1755876X.2019.1661564.

Toner, M., A. Kirwan Jr., L. Kantha, and J. Choi, 2001: Can general circulation models be assessed and their output enhanced with drifter data? J. Geophys. Res., 106, 19563-19579, https:// doi.org/10.1029/2000JC000587.

van den Bremer, T. S., and Ø. Breivik, 2018: Stokes drift. Philos. Trans. Roy. Soc. London, 376A, 20170104, https://doi.org/ 10.1098/rspa.2016.0159.

van Sebille, E., and Coauthors, 2015: A global inventory of small floating plastic debris. Environ. Res. Lett., 10, 124006, https:// doi.org/10.1088/1748-9326/10/12/124006.

WAMDI Group, 1988: The WAM model-A third generation ocean wave prediction model. J. Phys. Oceanogr., 18, 1775-1810, https://doi.org/10.1175/1520-0485(1988)018\% 3C1775:TWMTGO\%3E2.0.CO;2.

Xie, J., L. Bertino, F. Counillon, K. A. Lisæter, and P. Sakov, 2017: Quality assessment of the TOPAZ4 reanalysis in the Arctic over the period 1991-2013. Ocean Sci., 13, 123-144, https:// doi.org/10.5194/os-13-123-2017. 